\title{
Plasma concentration of C-reactive protein is increased in Type I diabetic patients without clinical macroangiopathy and correlates with markers of endothelial dysfunction: evidence for chronic inflammation
}

\author{
C.G. Schalkwijk ${ }^{1,3}$, D.C.W. Poland ${ }^{2}$,W. van Dijk ${ }^{2}$, A. Kok ${ }^{1}$, J.J. Emeis ${ }^{5}$, A. M. Dräger ${ }^{1}$, A. Doni ${ }^{4}$, \\ V.W.M. van Hinsbergh ${ }^{3,5}$, C.D. A. Stehouwer ${ }^{1,3}$ \\ ${ }^{1}$ Department of Clinical Chemistry, Haematology and Internal Medicine, Academic Hospital Vrije Universiteit, Amsterdam, \\ The Netherlands \\ ${ }^{2}$ Department of Medical Chemistry, Institute for Immunology and Inflammatory Diseases, Vrije Universiteit, Amsterdam, \\ The Netherlands \\ ${ }^{3}$ Institute for Cardiovascular Research, Vrije Universiteit, Amsterdam, The Netherlands \\ ${ }^{4}$ Istituto di Ricerche Farmacologiche 'Mario Negri', Milan, Italy \\ ${ }^{5}$ Gaubius Laboratory TNO-PG, Leiden, The Netherlands
}

Summary Moderately increased plasma concentrations of C-reactive protein are associated with an increased risk of cardiovascular disease. C-reactive protein, its relation to a low degree of inflammatory activation and its association with activation of the endothelium have not been systematically investigated in Type I (insulin-dependent) diabetes mellitus. $\mathrm{C}$-reactive protein concentrations were measured in 40 non-smoking patients with Type I diabetes without symptoms of macrovascular disease and in healthy control subjects, and in a second group of Type I diabetic patients $(n=60)$ with normo- $(n=20)$, micro$(n=20)$ or macroalbuminuria $(n=20)$. Differences in glycosylation of $\alpha_{1}$-acid glycoprotein were assayed by crossed affinity immunoelectrophoresis. Activation of the endothelium was measured with plasma concentrations of endothelial cell markers. The median plasma concentration of C-reactive protein was higher in Type I diabetic patients compared with healthy control subjects $[1.20(0.06-21.64)$ vs 0.51 (0.04-9.44) $\mathrm{mg} / \mathrm{l} ; p<0.02]$. The Type I diabetic subjects had a significantly increased relative amount of fucosylated $\alpha_{1}$-acid glycoprotein $(79 \pm 12 \%$ vs $69 \pm 14 \%$ in the healthy control subjects; $p<0.005$ ), indicating a chronic hepatic inflammatory response. In the Type I diabetic group, $\log (\mathrm{C}$-reactive protein $)$ correlated significantly with von Willebrand factor $(r=0.439, p<0.005)$ and vascular cell adhesion molecule-1 $(r=0.384, p<0.02)$, but not with sE-selectin $(r=0.008, p=0.96)$. In the second group of Type I diabetic patients, increased urinary albumin excretion was associated with a significant increase of von Willebrand factor $(p<0.0005)$ and C-reactive protein $(p=0.003)$, which were strongly correlated $(r=0.53$, $p<0.0005)$. Plasma concentrations of C-reactive protein were higher in Type I diabetic patients without (clinical) macroangiopathy than in control subjects, probably due to a chronic hepatic inflammatory response. The correlation of C-reactive protein with markers of endothelial dysfunction suggests a relation between activation of the endothelium and chronic inflammation. [Diabetologia (1999) 42: 351357]

Keywords Type I (insulin-dependent) diabetes mellitus, acute-phase response, C-reactive protein, atherosclerosis, inflammation, vascular disease, $\alpha_{1}$-acid glycoprotein, fucosylation.
Received: 4 September 1998 and in final revised form: 24 November 1998

Corresponding author: Dr. C.G. Schalkwijk, Department of Clinical Chemistry, Academic Hospital Vrije Universiteit, P. O. Box 7057, 1007 MB Amsterdam, The Netherlands
Abbreviations: AAL, Aleuria aurantia lectin; AER, urinary albumin excretion; AGP, $\alpha_{1}$-acid glycoprotein; Con A, concanavalin A; CRP, C-reactive protein, PTX3, pentraxin 3; sPLA $A_{2}$, secretory phospholipase $\mathrm{A}_{2}$; sVCAM-1, soluble vascular cell adhesion molecule-1; vWf, von Willebrand factor 
Diabetes mellitus is an independent risk factor for the development of atherosclerosis [1]. The mechanisms through which the enhanced risk of atherosclerosis is expressed are poorly understood but numerous observations support the theory that chronic low-degree inflammation is involved in the progression of atherosclerosis [2]. A feature of inflammatory activity is the increase in circulating plasma concentrations of acute-phase proteins produced by the liver such as C-reactive protein (CRP), secretory phospholipase $\mathrm{A}_{2}\left(\mathrm{sPLA}_{2}\right), \alpha_{1}$-acid glycoprotein (AGP) and fibrinogen. One of the most sensitive acute-phase proteins is CRP and during an acute inflammation the concentration can increase several hundredfold. Interest in CRP has grown rapidly during the last years, since it was shown that even a slightly increased production of CRP, within the 'normal' range, is associated with an increased risk of cardiovascular disease both in patients with angina pectoris [3] and in apparently healthly volunteers [4]. Diabetic patients have a high incidence of atherosclerosis and identification of patients at especially high risk for the development of atherosclerosis is of importance. Although increased circulating acute-phase proteins have been reported in diabetes $[5,6,7]$, plasma acute-phase proteins concentrations in Type I (insulin-dependent) diabetes mellitus have not been studied systematically. One aim of this study was therefore to measure concentrations of CRP and other acute-phase proteins in Type I diabetic subjects without symptoms of macroangiopathy. In order to discriminate between acute and chronic hepatic inflammatory responses, the state of glycosylation of AGP was investigated. In earlier studies it has been shown that during acute inflammation the diantennary glycan content as well as the degree of fucosylation of AGP is greatly increased [8-10]. In contrast, in various chronic inflammatory conditions only the degree of fucosylation is enhanced [10-13].

Activation of endothelial cells is thought to be an early step in atherogenesis and to have a central role in the pathogenesis of vascular diseases in diabetes $[14,15]$. The associations between markers of inflammation and endothelial cell activation, however, has not been studied. Therefore, the second aim of this study was to evaluate the association between increased CRP concentrations in Type I diabetic patients with markers of endothelial cell dysfunction. The endothelial cell activation markers studied were von Willebrand factor (vWf) and the soluble form of E-selectin. In addition, the soluble form of vascular cell adhesion molecule-1 (VCAM-1) was used as a vascular cell activation marker.
Table 1. Characteristics of the subjects in study A

\begin{tabular}{lll}
\hline & $\begin{array}{l}\text { Type I diabetic patients } \\
n=40\end{array}$ & $\begin{array}{l}\text { Healthy subjects } \\
n=40\end{array}$ \\
\hline Age (years) & $39.3(15.7)$ & $38.5(13.4)$ \\
$\mathrm{Sex}(\mathrm{M} / \mathrm{F})$ & $21 / 19$ & $21 / 19$ \\
$\mathrm{BMI}\left(\mathrm{kg} / \mathrm{m}^{2}\right)$ & $24.2(3.4)$ & $23.2(3.4)$ \\
$\mathrm{HbA}_{1 \mathrm{c}}(\%)$ & $8.0(1.4)$ & - \\
$\begin{array}{l}\text { Duration of diabetes } \\
\text { years) }\end{array}$ & $20.6(2-70)$ & - \\
$\begin{array}{l}\text { Normo-/ } \\
\text { microalbuminuria }\end{array}$ & $30 / 10$ & - \\
$\begin{array}{l}\text { Retinopathy: } \\
\text { no/background/ }\end{array}$ & & \\
proliferative & $24 / 13 / 3$ & $-/-/-$ \\
\hline
\end{tabular}

Data are mean (SD) or median (range), or number. Age, sex distribution and BMI did not differ significantly between the groups

\section{Subjects and methods}

Study A. After obtaining informed consent, 40 non-smoking patients with Type I diabetes, recruited from the out-patient clinic of the Academic Hospital Vrije Universiteit, Amsterdam, The Netherlands, were included in the study. Ten patients had microalbuminuria, defined as an urinary albumin excretion (AER) between 30 and $300 \mathrm{mg} / 24 \mathrm{~h}$ (median of $\geq 3$ urine collections) and 30 had normal urinary albumin excretion $(\mathrm{AER}<30 \mathrm{mg} / 24 \mathrm{~h})$. No patient had clinically proven macrovascular complications. On funduscopic examination, three patients had proliferative diabetic retinopathy, 13 had background retinopathy and 24 had no retinopathy. Forty nonsmoking and non-diabetic subjects of comparable age and sex distribution were recruited as a control group (Table 1). To exclude effects of seasonal variations, timing of blood sampling between control subjects and patients was matched.

We included 60 patients with Type I diabetes in the second part of this study (study B). These patients were recruited from the outpatient clinic of De Weezenlanden Hospital, Zwolle, The Netherlands. Patients were categorized into three groups based on the median AER of three $24 \mathrm{~h}$ urine samples as having normoalbuminuria, microalbuminuria or macroalbuminuria (AER above $300 \mathrm{mg} / 24 \mathrm{~h}$ ).

Blood sampling. Blood samples were drawn between 08.00 and 12.00 hours. Blood was collected in an EDTA vacutainer tube for the measurement of $\mathrm{HbA}_{1 \mathrm{c}}, \mathrm{CRP}$, fibrinogen and $\mathrm{sLA}_{2}$ and in CTAD (citrate theophylline, adenosine, dipyrimidole) Vacutainer tubes for determination of vWf, sE-selectin and sVCAM-1. Blood was drawn after a period of rest and with minimal occlusion of the vein. Plasma was prepared by $2000 \times g$ at $4{ }^{\circ} \mathrm{C}$ and stored in aliquots at less than $-20^{\circ} \mathrm{C}$ until assayed.

Laboratory procedures. Glycated haemoglobin $\left(\mathrm{HbA}_{1 \mathrm{c}}\right)$ was determined by high performance liquid chromatography (Bio-Rad Laboratories, Veenendaal, The Netherlands; reference range, $4.3-6.1 \%$ ). Plasma vWf antigen was measured by an ELISA, using rabbit anti-vWF antigen IgG as a catching antibody and a peroxidase-conjugated rabbit anti-vWF-antigen as detecting antibody (Dako, Copenhagen, Denmark). OPhenylenediamine (Sigma Chemical, St. Louis, USA) was used as substrate. Concentrations of vWf are expressed as per- 
Table 2. Plasma concentrations of acute-phase proteins and markers of endothelial function in subjects of Study A

\begin{tabular}{|c|c|c|c|}
\hline & Type I diabetic patients & Healthy subjects & $P$-value \\
\hline \multicolumn{4}{|c|}{ Acute-phase proteins: } \\
\hline $\mathrm{CRP}(\mathrm{mg} / \mathrm{l})$ & $\begin{array}{l}2.63 \pm 4.17 \\
1.20(0.06-21.64)\end{array}$ & $\begin{array}{l}1.15 \pm 1.93 \\
0.51(0.04-9.44)\end{array}$ & $0.015^{\mathrm{b}}$ \\
\hline Fibrinogen $(\mathrm{g} / \mathrm{l})$ & $\begin{array}{l}2.94 \pm 0.72 \\
3.00(1.60-4.10)\end{array}$ & $\begin{array}{l}2.90 \pm 0.65 \\
2.70(2.00-4.70)\end{array}$ & $0.78^{\mathrm{a}}$ \\
\hline $\mathrm{sPLA}_{2}(\mu \mathrm{g} / \mathrm{l})$ & $\begin{array}{l}4.77 \pm 3.61 \\
3.20(1.25-14.31)\end{array}$ & $\begin{array}{l}3.46 \pm 2.07 \\
2.72(1.56-11.85)\end{array}$ & $0.065^{\mathrm{b}}$ \\
\hline \multicolumn{4}{|c|}{ Markers of endothelial/vascular function: } \\
\hline vWf antigen $(\%)$ & $\begin{array}{l}129.8 \pm 57.9 \\
118.5(51-304)\end{array}$ & $\begin{array}{l}101.7 \pm 37.9 \\
88.0(34.0-192)\end{array}$ & $0.013^{\mathrm{b}}$ \\
\hline sE-selectin $(\mu \mathrm{g} / \mathrm{l})$ & $\begin{array}{l}47.2 \pm 16.4 \\
45.0(16-97)\end{array}$ & $\begin{array}{l}35.3 \pm 13.6 \\
39.0(14.0-65.0)\end{array}$ & $0.013^{\mathrm{a}}$ \\
\hline
\end{tabular}

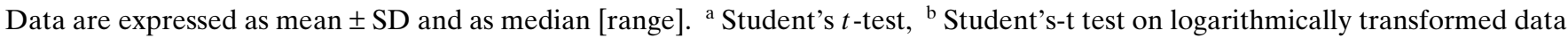

centage of antigen concentrations in normal pooled plasma, which is defined as $100 \%$. The intra- and inter-assay coefficients of variation are $2.3 \%$ and $3.8 \%$, respectively. Soluble (s) E-selectin and sVCAM-1 were measured by ELISA kits (R\&D Systems, Oxon, UK). The intra- and inter-assay coefficients of variation for sVCAM-1 are less than $5.9 \%$ and less than $10.2 \%$ and for sE-selectin less than $5 \%$ and less than $9.1 \%$, as reported by the manufacturer. Fibrinogen was measured on a STA compact (Boehringer Mannheim, Almere, The Netherlands) according to a functional assay (Clauss method). CRP was measured with a sensitive in-house ELISA with rabbit anti-CRP (Dako, Copenhagen, Denmark) as a catching and a tagging antibody as described previously [16], with intra- and inter-assay coefficients of variation of $3.8 \%$ and $4.7 \%$, respectively. Antigen concentrations of $\mathrm{sPLA}_{2}$ in plasma were measured with a sensitive ELISA as previously described [17]. Pentraxin 3 (PTX3) was measured with an ELISA as described previously [18].

AGP was measured by nephelometry with the Beckman Array 360 System, Mijdrecht, The Netherlands. Differences in glycosylation of AGP were assayed by crossed affinity immunoelectrophoresis with Aleuria aurantia lectin (AAL) or concanavalin A (Con A) [11]. In the first dimension gel, AAL was used as the affinity component to analyse the fucosylation and Con A was used to analyse the degree of branching of the glycans on AGP. AAL (2.5 g/l) retards AGP glycoforms expressing $\alpha 3$-linked fucose residues on the $\mathrm{N}$-linked complex type glycans. Con A ( $2 \mathrm{~g} / \mathrm{l})$ retards AGP molecules containing one or more diantennary $\mathrm{N}$-linked glycans of the complex type [13]. In short, aliquots of sera containing $0.8 \mu \mathrm{g}$ AGP were electrophoresed in an AAL- or Con A-containing 7\% polyacrylamide gel, resulting in a separation of different AGP-glycoforms. In the second, perpendicular, dimension, these glycoforms were immunoelectrophoresed against precipitating monospecific rabbit anti-human AGP polyclonal antibodies (prepared by Dr A. Mackiewicz, Poznan, Poland). Coomassie Brillant Blue R250 (Sigma, St. Louis, Mo., USA) was used to visualise the resulting precipitation curves. The areas under the precipitation curves were determined using a Summagraph (ACECAD D-9000) and an area measurement programme was used to calculate the relative amounts of separated AGP glycoforms.
Statistical analysis. Results are expressed as means \pm SD or as median (ranges). Statistical differences between groups of data distributed parametrically (vWF, AGP, fibrinogen, sE-selectin, sVCAM-1) were tested by Student's $t$-test. Data distributed non-parametrically (CRP, sPLA $)_{2}$ ), as determined with Kolmogorov-Smirnov analysis $(p<0.05)$, were logarithmically transformed to obtain a normal distribution and, after checking that this was indeed the case, statistical differences were analysed by Student's $t$-test. Correlations were estimated according to Pearson. Differences among normoalbuminuric, microalbuminuric and macroalbuminuric subjects were analysed using ANOVA. A two-tailed $P$-value of less than 0.05 was considered significant. All calculations were done using SPSS version 6.1.

\section{Results}

Study A (Tables 1-4). Among the various acute-phase proteins measured, the median plasma concentration of CRP was 2.5 -fold higher in the diabetic group compared with the control subjects $(p<0.02)$ (Table 2$)$. The median plasma concentrations of $\mathrm{SPAA}_{2}$ and fibrinogen were slightly, but not significantly, higher in the diabetic group. In the diabetic group, $\log (\mathrm{CRP})$ was highly correlated with $\log \left(\mathrm{sPLA}_{2}\right)$ and AGP, but not with fibrinogen (Table 3), while in the control group $\log (\mathrm{CRP})$ was highly correlated with fibrinogen $(r=0.60, p<0.001)$ and also with AGP $(r=0.36$, $p<0.05)$, but not with $\log \left(\mathrm{sPLA}_{2}\right) \quad(r=0.19$, $p=0.24)$. Further analysis in the diabetic group showed a significant correlation of $\log (\mathrm{CRP})$ with BMI and glycaemic control, but not with duration of Type I diabetes (Table 3$)$ and age $(r=0.26)$. In the control group $\log (\mathrm{CRP})$ was not significantly correlated with BMI $(r=0.23)$ or age $(r=0.02)$. The correlation between BMI and $\log (\mathrm{CRP})$ in the Type I diabetic patients was significantly different from that in the control subjects $(p<0.0005)$. 
Table 3. Pearson correlation coefficients with $p$-values in 40 non-smoking Type I diabetic patients without macroangiopathy in Study A

\begin{tabular}{|c|c|c|c|c|c|c|c|c|c|}
\hline AGP & $\begin{array}{l}0.56 \\
<0.0005\end{array}$ & & & & & & & & \\
\hline Fibrinogen & $\begin{array}{l}0.26 \\
0.11\end{array}$ & $\begin{array}{l}0.17 \\
0.28\end{array}$ & & & & & & & \\
\hline $\log \left(\right.$ sPLA $\left._{2}\right)$ & $\begin{array}{l}0.58 \\
<0.0005\end{array}$ & $\begin{array}{l}0.58 \\
<0.0005\end{array}$ & $\begin{array}{l}0.29 \\
0.07\end{array}$ & & & & & & \\
\hline vWf & $\begin{array}{l}0.44 \\
0.005\end{array}$ & $\begin{array}{l}0.38 \\
0.02\end{array}$ & $\begin{array}{l}0.31 \\
0.05\end{array}$ & $\begin{array}{l}0.32 \\
0.05\end{array}$ & & & & & \\
\hline sE-selectin & $\begin{array}{l}0.01 \\
0.96\end{array}$ & $\begin{array}{l}0.23 \\
0.16\end{array}$ & $\begin{array}{l}0.27 \\
0.09\end{array}$ & $\begin{array}{l}0.10 \\
0.53\end{array}$ & $\begin{array}{l}0.10 \\
0.55\end{array}$ & & & & \\
\hline sVCAM-1 & $\begin{array}{l}0.38 \\
0.01\end{array}$ & $\begin{array}{l}0.23 \\
0.15\end{array}$ & $\begin{array}{l}0.33 \\
0.04\end{array}$ & $\begin{array}{l}0.46 \\
0.003\end{array}$ & $\begin{array}{l}0.62 \\
<0.0005\end{array}$ & $\begin{array}{l}-0.14 \\
0.38\end{array}$ & & & \\
\hline $\mathrm{HbA}_{1 \mathrm{c}}$ & $\begin{array}{l}0.34 \\
0.03\end{array}$ & $\begin{array}{l}0.25 \\
0.12\end{array}$ & $\begin{array}{l}0.33 \\
0.04\end{array}$ & $\begin{array}{l}0.19 \\
0.24\end{array}$ & $\begin{array}{l}0.40 \\
0.01\end{array}$ & $\begin{array}{l}0.54 \\
<0.0005\end{array}$ & $\begin{array}{l}0.13 \\
0.43\end{array}$ & & \\
\hline \multirow[t]{2}{*}{ BMI } & $\begin{array}{l}0.64 \\
<0.0005\end{array}$ & $\begin{array}{l}0.44 \\
0.01\end{array}$ & $\begin{array}{l}0.23 \\
0.14\end{array}$ & $\begin{array}{l}0.31 \\
0.08\end{array}$ & $\begin{array}{l}0.44 \\
0.01\end{array}$ & $\begin{array}{l}0.10 \\
0.59\end{array}$ & $\begin{array}{l}0.05 \\
0.81\end{array}$ & $\begin{array}{l}0.25 \\
0.17\end{array}$ & $\begin{array}{l}0.28 \\
0.12\end{array}$ \\
\hline & $\log (\mathrm{CRP})$ & AGP & Fibrinogen & $\log \left(\mathrm{sLA}_{2}\right)$ & vWf & sE-selectin & sVCAM-1 & $\mathrm{HbA}_{1 \mathrm{c}}$ & $\begin{array}{l}\text { Duration of } \\
\text { Type I diabetes }\end{array}$ \\
\hline
\end{tabular}

Table 4. Reactivities of $\alpha_{1}$-acid glycoprotein (AGP) with concanavalin A (Con A) and Aleuria aurantia lectin (AAL) in plasma from Type I diabetic patients and healthy subjects in Study A

\begin{tabular}{llll}
\hline & $\begin{array}{l}\text { Type I diabetic } \\
\text { patients }\end{array}$ & $\begin{array}{l}\text { Healthy } \\
\text { subjects }\end{array}$ & $p$-value \\
\hline $\begin{array}{l}\text { Con A-reactivity: } \\
\begin{array}{l}\text { AGP fraction with } \\
\text { diantennary glycans (\%) }\end{array}\end{array}$ & $51 \pm 10$ & $53 \pm 12$ & $0.55^{\mathrm{a}}$ \\
$\begin{array}{l}\text { AAL-reactivity: } \\
\begin{array}{l}\text { AGP fraction with } \\
\text { fucosylated glycans (\%) }\end{array}\end{array}$ & $79 \pm 12$ & $69 \pm 14$ & $0.005^{\mathrm{a}}$ \\
\hline
\end{tabular}

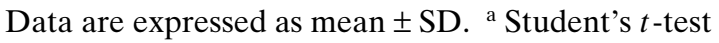

When the 10 patients with microalbuminuria were excluded from analysis, the difference between the median plasma concentration of CRP in control subjects and the 30 patients with normoalbuminuria remained significant $\left[\begin{array}{lll}0.51 & (0.04-9.44)\end{array}\right]$ vs 1.25 (0.06-21.64) $\mathrm{mg} / \mathrm{l}, p=0.02]$. Similarly, the median plasma concentrations of CRP remained significantly increased when we excluded Type I diabetic patients with microalbuminuria or retinopathy or both $[1.22$ (0.06-21.64) $\mathrm{mg} / \mathrm{l}(n=22), p=0.02]$.

CRP belongs to the pentraxin family of proteins [19]. To study whether increased concentrations of CRP are a general phenomenon of increased expression of proteins of the pentraxin family, we measured PTX3, another member of this family, although not classified as an acute-phase protein. No differences in the mean concentrations of PTX3 were found be- tween the groups $(0.425 \pm 0.315 \mu \mathrm{g} / 1$ in the control subjects vs $0.432 \pm 0.341 \mu \mathrm{g} / \mathrm{l}$ in Type I diabetes, $p=0.94)$. In the Type I diabetic and control group, PTX3 did not correlate with $\log (\mathrm{CRP})$.

To discriminate between acute and chronic hepatic inflammatory responses; we determined the degree of branching and fucosylation of AGP. No significant difference in diantennary glycan content could be detected between AGP from the control group and the Type I diabetic patients (Table 4). In contrast, distinct differences in degree of fucosylation of AGP were found between the diabetic and control group (Fig. $1)$. In the diabetic group, the degree of fucosylation of AGP was not significantly correlated with $\mathrm{HbA}_{1 \mathrm{c}}$ $(r=0.23)$. In the Type I diabetic group, a significant increase in the fraction of AGP retarded by the fucose-specific lectin AAL was found compared with the control subjects (Table 4). In the total group there was a trend for a correlation between the degree of fucosylation of AGP and $\log (\mathrm{CRP})(r=0.21$, $p=0.10)$.

To evaluate whether increased CRP concentrations were associated with activation of the endothelium, we measured plasma concentrations of markers of endothelial function. Plasma concentrations of vWf and sE-selectin were significantly higher in the Type I diabetic than in the control group, whereas the vascular activation marker sVCAM-1 was not (Table 2). In the diabetic group, $\log (\mathrm{CRP})$ correlated significantly with vWF and sVCAM-1, which is illustrated in Figure 2, while it was not correlated with sE-selectin (Table 3). In the control group, log 
Table 5. Characteristics of Type I diabetic patients in Study B

\begin{tabular}{llcr}
\hline & $\begin{array}{l}\text { Normoalbuminuria } \\
(n=20)\end{array}$ & $\begin{array}{l}\text { Microalbuminuria } \\
(n=20)\end{array}$ & $\begin{array}{l}\text { Macroalbuminuria } \\
(n=20)\end{array}$ \\
\hline Age (years) & $37.4(17.7)$ & $46.6(20.5)$ & $55.8(11.6)$ \\
Diabetes duration (years) & $11.0(7.8)$ & $17.9(8.6)$ & $18.9(10.9)$ \\
BMI (kg/m $\left.{ }^{2}\right)$ & $24.4(4.2)$ & $25.9(4.1)$ & $25.0(3.2)$ \\
HbA $_{1 \mathrm{c}}(\%)$ & $8.6(3.3)$ & $8.4(1.9)$ & $9.2(2.3)$ \\
Albuminuria $(\mu \mathrm{g} / \mathrm{min})$ & $7(5)$ & $77(45)$ & $1212(819)$ \\
\hline
\end{tabular}

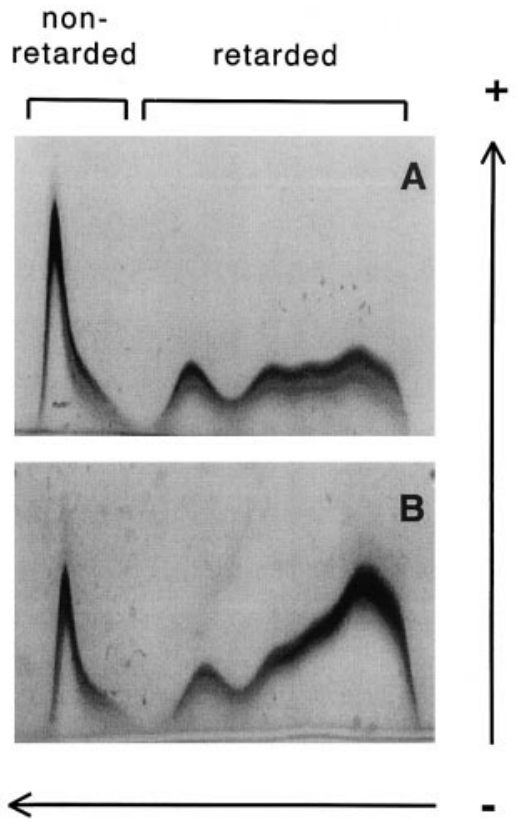

Fig.1A, B. Representative crossed affinity immunoelectrophoresis pattern, obtained with the fucose specific lectin AAL, of a control subject (A) and a patient with Type I diabetes (B). The non-retarded fraction contains the AGP molecules without fucosylated glycans. The retarded fraction shows an increased amount of fucosylated AGP molecules in Type I diabetic subjects as compared with control subjects. The bottom arrows indicate the direction of the electric field for the first dimension electrophoreses with the use of the fucose specific lectin AAL. The right arrow indicates the direction of the electric field for the second dimension electrophoreses in which the AGP molecules precipitate with the AGP antibodies. (A) AAL reactivity of AGP of a healthy control subject; this pattern is characterised by a high percentage of non-retarded AGP. (B) AAL reactivity of AGP of a Type I diabetic patient; this pattern is characterised by an increased percentage of retarded AGP. Without the fucose-specific lectin AAL, AGP would not be retarded

(CRP) did not correlate significantly with vWf, sVCAM-1, or sE-selectin (not shown).

Study B (Table 5). We extended our study by measuring plasma concentrations of CRP and vWf in additional Type I diabetic patients (Table 5). Increased AER was associated with a significant increase of vWf across the three groups $(143 \pm 47,160 \pm 39$ and $218 \pm 71 \%$, respectively; $p<0.005$ ). In parallel to vWf, CRP concentrations increased across the three groups $[0.84(0.24-10.68), \quad 1.32(0.24-22.92)$ and 5.7(0.48-53.28) mg/l, respectively; $p<0.005$ ] (Fig.3). The increase in CRP and vWf concentrations across the three groups remained when adjusted for age $(p<0.005)$. In the total group, CRP was strongly correlated with $\mathrm{vWf}(r=0.53, p<0.0005)$.

\section{Discussion}

The main finding of this study was a higher plasma concentration of CRP in Type I diabetic patients without clinical macrovascular disease compared with control subjects. This remained significant even when diabetic subjects with microalbuminuria were excluded from the analysis. Furthermore, we found that fucosylation of AGP in Type I diabetic patients was increased, which indicates a chronic rather than acute inflammatory phenomenon. In the diabetic group, CRP correlated with vWF and sVCAM-1, suggesting a relation between chronic inflammation and endothelial dysfunction.

The median CRP concentration in the control subjects was $0.51 \mathrm{mg} / \mathrm{l}$, which corresponds with a median CRP concentration of $0.64 \mathrm{mg} / 1$ in healthy subjects [20]. It has been shown that the plasma concentration of CRP is determined only by its production rate [21], suggesting that the increased concentrations of CRP in Type I diabetes are not due to impaired clearance kinetics. Plasma concentrations of PTX3 were not different between Type I diabetic patients and control subjects, indicating that the increased concentrations of CRP are not a general phenomenon of increased expression of proteins of the pentraxin family but more likely reflect an acute-phase hepatic inflammatory response.

The acute-phase response is a general non-specific response to tissue damage and inflammation. The glycosylation of AGP, one of the positive acute phase proteins, enabled us to discriminate between acute or chronic inflammation. Previously, we have shown an increase in both the amount of diantennary glycans as well as the degree of fucosylation during acute inflammation [8-10]. In contrast, chronic inflammation is characterised by an increase in fucosylation and not accompanied by a change in diantennary glycan content [10-12]. In this study, no important difference in ConA reactivity of AGP was found between the 

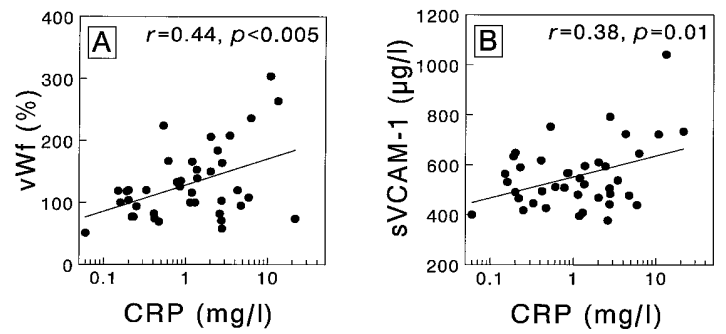

Fig. 2 A, B. Relation between C-reactive protein and the plasma concentrations of endothelial cell function markers von Willebrand factor (A) and vascular cell adhesion molecule-1 (B) in Type I diabetes. Pearson's correlation coefficients are presented between $\log (\mathrm{CRP})$ and vWf $(\mathbf{A})$ and sVCAM-1 (B)

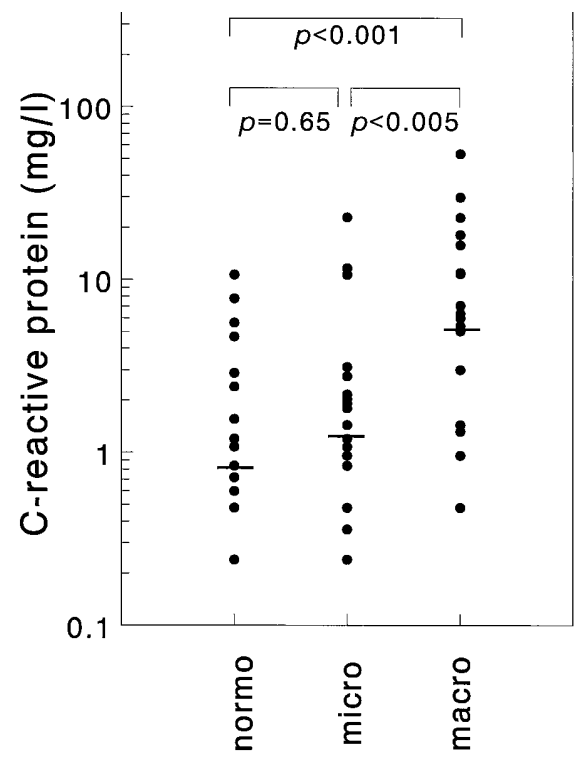

Fig.3. The distribution of C-reactive protein in Type I diabetic patients categorized as normoalbuminuric (normo), microalbuminuric (micro) and macroalbuminuric (macro) in study B (Table 5). Horizontal lines denote medians

control and the Type I diabetic group. In contrast, important changes could be shown in AAL reactivity of AGP from the Type I diabetic patients compared with the control subjects. This suggests that the increased reactivity of AGP to AAL reflects a chronic inflammatory response. It should be emphasized that hyperglycaemia per se did not affect fucosylation or secretion of fucosylated proteins $[22,23]$. In agreement, we found no correlation between the degree of fucosylation and $\mathrm{HbA}_{1 \mathrm{c}}$ concentrations.

Various possible mechanisms could induce chronic low-degree inflammation in diabetes, including activation of macrophages, increased oxidative stress or an induction of cytokines. One of the pathophysiological consequences of hyperglycaemia is the phenomenon of nonenzymatic glycation and the formation of advanced glycation end products (AGEs) [24]. AGEs have been shown to activate macrophages [25], to increase oxidative stress [26] and to induce, in macro- phages, the synthesis of interleukin-1 and tumor necrosis factor- $\alpha$ [27] and, in vivo in mice, the expression of interleukin- 6 mRNA [28]. Many of the possible mechanisms leading to chronic low-degree inflammation could be related to nonenzymatic glycation. Another possibility is that increases in CRP are related to adipose-tissue-derived cytokines [29]. Note that we found a much stronger correlation between BMI and CRP in the Type I diabetic patients than in the control subjects. The role of adipose tissue as a possible cause of chronic inflammatory activity in Type I diabetes thus requires further investigation.

In the light of observations that microalbuminuria is an independent risk factor for severe micro- and macroangiopathy in Type I diabetes [30-32], it must be noted that we found increased concentrations of CRP even in normoalbuminuric patients (Table 2) and a further increase with increasing albuminuria. The development of urinary albumin excretion is believed to be accompanied by a generalized impairment of vascular function [15], and we observed indeed that vWf increased with increasing albuminuria in Type I diabetic patients. In addition, we found a relatively strong correlation between CRP and vWf in Type I diabetes; increases in the latter might precede the development of microalbuminuria [33]. Endothelial dysfunction possibly provides a link between inflammation and atherothrombotic disease. These data indicate that raised CRP concentrations are associated with endothelial activation and that the increase in CRP concentrations in Type I diabetes is not caused by the development or presence of microvascular complications but might precede these. This and other human population studies, however, do not prove whether CRP is the cause or the consequence of the process of vascular disease, or both.

In conclusion, plasma concentrations of CRP were higher in Type I diabetic patients without macroangiopathy than in control subjects, which resulted most probably from a systemic low-degree chronic hepatic inflammatory response as indicated by the type of change in glycosylation of AGP. The increase in fucosylation of AGP and the correlation between the concentrations of CRP and vWf and sVCAM-1 suggest a relation between chronic inflammation, activation of the endothelium and vascular diseases in Type I diabetes.

Acknowledgements. We thank Dr. H. J. G. Bilo for his cooperation with recruiting Type I diabetic patients. Dr. C.D. A. Stehouwer is supported by a Clinical Research Fellowship from the Diabetes Fonds Netherland and the Netherlands Organization for Scientific Research (NWO). 


\section{References}

1. Kannel WB, McGee DL (1979) Diabetes and cardiovascular disease. The Framingham study. JAMA 241: 2035-2038

2. Ross R (1993) The pathogenesis of atherosclerosis: a perspective for the 1990s. Nature 362: 801-809

3. Haverkate F, Thompson SG, Pyke SDM, Gallimore JR, Pepys MM (1997) Production of C-reactive protein and risk of coronary events in stable and unstable angina. Lancet 349: 426-466

4. Ridker PM, Cushman M, Stampfer MJ, Tracy RP, Hennekens CH (1997) Inflammation, aspirin, and the risk of cardiovascular disease in apparently healthy men. N Engl J Med 336: 973-979

5. Pickup JC, Mattock, MB, Chusney, GD, Burt D (1997) NIDDM as a disease of the innate immune system: association of acute-phase reactants and interleukin- 6 with metabolic syndrome X. Diabetologia 40:1286-1292

6. McMillan DE (1979) Increased levels of acute-phase serum proteins in diabetes. Metabolism 38:1042-1046

7. Myrup B, de Maat M, Rossing P, Gram J, Kluft C, Jespersen J (1996) Elevated fibrinogen and the relation to acute phase response in diabetic nephropathy. Throm Res 81: 485-490

8. Pos O, Van der Stelt ME, Wolbink GJ, Nijsten MWN, Van der Tempel GL, Van Dijk W (1990) Changes in the serum concentration and the glycosylation of human $\alpha_{1}$-acid glycoprotein and $\alpha_{1}$-protease inhibitor in severely burned patients: relation to interleukin-6 levels. Clin Exp Immunol 82: $579-582$

9. Mackiewicz A, Marcinkowska-Pieta R, Ballou S, Mackiewicz S, Kushner I (1987) Microheterogeneity of $\alpha_{1}$-acid glycoprotein in the detection of intercurrent infection in systemic lupus erythematosus. Arthritis Rheum 30: 513-518

10. De Graaf TW, Van Ommen ECR, Van der Stelt ME, Kerstens PJSM, Boerbooms AMTH, Van Dijk W (1994) Effects of low-dose methotrexate therapy on the concentration and the glycosylation of $\alpha_{1}$-acid glycoprotein in the serum of rheumatoid arthritis patients: A longitudinal study. J Rheumatol 21: 2209-2216

11. De Graaf TW, Van der Stelt ME, Anbergen MG, Van Dijk W (1993) Inflammation-induced expression of sialyl Lewis $\mathrm{X}$-containing glycan structures on $\alpha_{1}$-acid glycoprotein (orosomucoid) in human sera. J Exp Med 177: 657-666

12. Van Dijk W, Brinkman-van der Linden ECM, Havenaar EC (1998) $\alpha_{1}$-Acid glycoprotein (orosomucoid): pathophysiological changes in glycosylation in relation to its function. Adv Exp Med Biol 435: 145-150

13. Bierhuizen MFA, De Wit M, Govers C et al. (1988) Glycosylation of three molecular forms of human $\alpha_{1}$-acid glycoprotein having different interactions with concanavalin A. Variations in the occurance of di-, tri-, and tetraantennary glycans and the degree of sialylation. Eur J Biochem 175: 387-394

14. Hamsten A (1995) Hemostatic function and coronary artery disease. N Engl J Med 332: 677-678

15. Stehouwer CDA, Lambert J, Donker AJM, Van Hinsbergh VWM (1997) Endothelial dysfunction and pathogenesis of diabetic angiopathy. Cardiovasc Res 34: 55-68

16. Highton J, Hessian PA (1984) A solid-phase enzyme immunoassay for C-reactive protein: clinical value an the effect of rheumatoid factor. J Immunol Methods 68: 185-192

17. Wolbink GJ, Schalkwijk CG, Baars JW, Wagstaff J, Van den Bosch H, Hack CE (1995) Therapy with interleukin-2 induces the systemic release of phospholipase $\mathrm{A}_{2}$. Cancer Immunol Immunother 41: 287-292
18. Bottazzi B, Vouret-Craviari V, Bastone A et al. (1997) Multimer formation and ligand recognition by the long pentraxin PTX3: similarities and differences with the short pentraxins $\mathrm{C}$ reactive proteins and serum amyloid $\mathrm{P}$ component. J Biol Chem 272: 32817-32829

19. Introna M, Alles VV, Castellano M et al. (1996) Cloning of mouse pt $\times 3$, a new member of the pentraxin gene family expressed at extrahepatic sites. Blood 87: 1862-1872

20. Macy EM, Hayes TE, Tracy RP (1997) Variability in the measurement of C-reactive protein in healthy subjects: implications for reference intervals and epidemiological applications. Clin Chem 43: 52-58

21. Vighushin DM, Pepys MB, Hawkins PN (1993) Metabolic and scintigraphic studies of radiodinated human C-reactive protein in health and disease. J Clin Invest 91: 1351-1357

22. Wiese TJ, Dunlap JA, Yorek MA (1997) Effect of L-fucose and D-glucose concentration on L-fucoprotein metabolism in human Hep G2 cells and changes in fucosyltransferase and $\alpha$-L-fucosidase activity in liver of diabetic rats. Biochim Biophys Acta 1335: 61-72

23. Ronquist G, Walinder O (1983) Increased activity of serum fucosyltransferase in diabetic patients. Diabete Metabolisme 9: 212-216

24. Vlassara H, Bucala R, Striker L (1994) Pathogenic effects of advanced glycosylation: Biochemical, biological and clinical implications for diabetes and aging. Lab Invest 70 : 138-151

25. Kirstein M, Brett J, Radoff S, Ogawa S, Stern D, Vlassara H (1990) Advanced protein glycation induces transendothelial human monocyte chemotaxis and secretion of PDGF: role in vascular disease of diabetes and aging. Proc Natl Acad Sci USA 87: 9010-9014

26. Yan SD, Schmidt AM, Anderson GM et al. (1994) Enhanced cellular oxidant stress by the interaction of advanced glycation endproducts with their receptors/binding proteins. J Biol Chem 268: 9889-9897

27. Vlassara H, Brownlee M, Manogue HR, Dinarello C, Pasagian A (1988) Cachetin/TNF and IL-1 induced by glucose modified proteins: role in normal tissue remodeling. Science 240: 1546-1548

28. Schmidt AM, Hasu M, Popov M et al. (1994) Receptor for advanced glycation end products (AGEs) has a central role in vessel wall interaction and gene activation in response to circulating AGE proteins. Proc Natl Acad Sci USA 91: 8807-8811

29. Hotamisligil GS, Arner, P, Caro JF, Atkinson RL, Spiegelman BM (1995) Increased adipose tissue expression of tumor necrosis factor-alpha in human obesity and insulin restistance. J Clin Invest 95: 2409-2415

30. Mogensen CE (1984) Microalbuminuria predicts clinical proteinuria and early mortality in maturity-onset diabetes mellitus. N Eng J Med 310: 356-360

31. Deckert T, Feldt-Rasmussen B, Borch-Johnsen K, Jensen T, Kofoed-Enevoldsen A (1989) Albuminuria reflects widespread vascular damage: the Steno hypothesis. Diabetologia 31: 219-226

32. Messent JWC, Elliot TG, Hill RD, Jarrett RJ, Keen H, Viberti GC (1992) Prognostic significance of microalbuminuria in insulin-dependent diabetes mellitus; a 23-year follow up study. Kidney Int 41: 836-839

33. Stehouwer CDA, Fischer HRA, Van Kuijk AWR, Polak BCP, Donker AJM (1995) Endothelial dysfunction precedes development of microalbuminuria in IDDM. Diabetes 444: 561-564 